1405

\section{RISK FACTORS FOR CANDIDEMIA IN A NEONATAL INTENSIVE CARE UNIT}

L. Decembrino ${ }^{1}$, S. Perrini ${ }^{1}$, A. De Silvestri ${ }^{2}$, R. Cabano ${ }^{1}$, S. Longo ${ }^{1}$, M. Stronati ${ }^{1}$

${ }^{1}$ Neonatal Intensive Care Unit, ${ }^{2}$ Biometri Unit, Fondazione IRCCS Policlinico, San Matteo, Pavia, Italy

Introduction: Candidiasis are important nosocomial infections in Neonatal Intensive Care Units (NICU) associated with prolonged morbidity and significant hospital costs. The incidence is reported as 2 $6.8 \%$ among VLBW and $4-16 \%$, among ELBW. The mortality rates is reported to be 30 to $60 \%$.

Objective: to identify the risk factors and clinical outcome associated with candidaemia.

Methods: retrospective study of all cases of fungal infections in our NICU between 2003 and 2009.

Results: 48 newborns were infected by Candida spp; $17 / 48$ (35.4\%) developed sepsis, 1/17 developed meningitis. Median GA was $25+3$ wks (23 - 35 wks). 12/17 (70\%) were < 28 wks. Median BW was $893 \mathrm{~g}$ (433-2050 g). 13/17 (76\%) were < $1000 \mathrm{~g}$. Isolated fungi were Candida Albicans (94\%) and Candida Glabrata (6\%). At univariate analysis, CVC (OR 69.5; $p<0.001$ ), CVO (OR 31.5; $p<0.001$ ), cephalosporin (OR 3.4; $p=0.05$ ), $\mathrm{H} 2$ antagonist (OR $6.6 ; p=0.004$ ), lipid emulsions (OR 110.0; $p<0.001$ ), ventilation (OR 17.5; $p<0.001$ ) were associated with sepsis. At multivariate analysis, ventilation and CVC remained significantly associated (OR 19.8 and $23.1 p=0.021$ and $p=0.005$ respectively). 8/17 (46\%) developed ROP, 1/17 (6\%) NEC, 3/17 (17\%) IVH. Median hospitalization was 91 days, median age at diagnosis was 20 days. 1/17 newborns died $(6 \%)$. All infants received liposomal amphotericin for a median time of 20 days.

Conclusions: ventilation, centralvascular catheters, third generation cephalosporins, $\mathrm{H} 2$ antagonist, lipid emulsions are significant risk factors for neonatal acquired candidemia. The incidence might be decreased by the judicious use of treatments identified as risk factors
1406

\section{NOCTURNAL MELATONIN CONCENTRATION IN PEDIATRIC INTENSIVE CARE PATIENTS WITH SEPSIS}

\author{
S. Bagci ${ }^{1}$, Ö.Ö. Horoz ${ }^{2}$, D. Yildizdas ${ }^{2}$, \\ J. Reinsberg ${ }^{3}$, G. Strackbein ${ }^{1}$, P. Bartmann"1, \\ A. Müller ${ }^{1}$
}

${ }^{1}$ Neonatology, University of Bonn, Bonn, Germany, ${ }^{2}$ Division of Pediatric Intensive Care, Department of Pediatrics, Faculty of Medicine, Cukurova

University, Adana, Turkey, ${ }^{3}$ Department of Gynecological Endocrinology, University of Bonn, Bonn, Germany

Introduction: Considering the potential immunomodulatory role of melatonin and its direct antioxidant activity, disturbances of the melatonin secretion pattern in the septic conditions could be particularly unfavorable. The aim of this study was to evaluate the nocturnal melatonin concentration (NMC) in children with sepsis at the pediatric intensive care unit (PICU).

Material and Methods: This observational study involved 15 septic and 14 non-septic patients at the PICU, University of Cukurova, Adana, Turkey. An eye mask was used between $8 \mathrm{pm}$ and $8 \mathrm{am}$ in all patients. Blood samples for the determination of NMC were obtained from each patient at 3 am on day $1,2,3,5$ and 10 .

Results: The median NMCs were not significantly different between septic and non-septic patients: Median(IQR), $\quad 89.6 \mathrm{pg} / \mathrm{ml} \quad(39.1-168.9 \mathrm{pg} / \mathrm{ml})$ and $61.3 \mathrm{pg} / \mathrm{ml} \quad(28.5-133.5 \mathrm{pg} / \mathrm{ml}) ; 102.2 \mathrm{pg} / \mathrm{ml} \quad$ (50.0$441.2 \mathrm{pg} / \mathrm{ml})$ and $59.0 \mathrm{pg} / \mathrm{ml} \quad(16.4-293.0 \mathrm{pg} / \mathrm{ml})$; $73.8 \mathrm{pg} / \mathrm{ml}(39.7-406.2 \mathrm{pg} / \mathrm{ml})$ and $97.0 \mathrm{pg} / \mathrm{ml}(26.5-$ $154.2 \mathrm{pg} / \mathrm{ml}) ; \quad 78.1 \mathrm{pg} / \mathrm{ml} \quad(38.6-179.3 \mathrm{pg} / \mathrm{ml})$ and $153.4 \mathrm{pg} / \mathrm{ml} \quad(45.5-231.1 \mathrm{pg} / \mathrm{ml}) ; \quad 86.8 \mathrm{pg} / \mathrm{ml} \quad(21.1-$ $137.5 \mathrm{pg} / \mathrm{ml})$ and $120.6 \mathrm{pg} / \mathrm{ml}(17.0-208.3 \mathrm{pg} / \mathrm{ml})$ at day $1,2,3,5$ and 10 , respectively $(p>0.05)$. The septic patients showed no significant changes of NMCs between day 1 and each other study day $(p>0.05)$. Presence of catecholamine, sedation and mechanical ventilation had no effect on the NMCs in septic patients $(p>0.05)$. There was no correlation between severity of disease (PRISM-II-Score) and NMC on day 1 ( $p>0.05)$.

Conclusion: The present study showed that the NMC is not affected in septic PICU patients despite severe disease and it is independent of the treatment. Further investigations are needed to identify any additional benefits of the treatment with melatonin in PICU patients with sepsis. 